\title{
Entrepreneurship in Market Process
}

\author{
Xiaobin Peng \\ College of Economics, Jinan University, Guangzhou, China \\ Email: pengxiaobin2019@163.com
}

How to cite this paper: Peng, X.B. (2019) Entrepreneurship in Market Process. Modern Economy, 10, 575-585.

https://doi.org/10.4236/me.2019.103039

Received: February 1, 2019

Accepted: February 26, 2019

Published: March 1, 2019

Copyright $\odot 2019$ by author(s) and Scientific Research Publishing Inc. This work is licensed under the Creative Commons Attribution International License (CC BY 4.0).

http://creativecommons.org/licenses/by/4.0/

\begin{abstract}
Based on the market process theory of the Austrian School of Economics, the article explores entrepreneurship in the market process, pointing out that market process is opposite to statics equilibrium. Under statics equilibrium, it is hard to analyze entrepreneurship by economics. Entrepreneurship only exists in the market process. The article argues that in market process, entrepreneurship is reflected in entrepreneur' behavior, including undertaking the uncertainty of business, combining heterogeneous capital, building the structure of capital. Profit-driven entrepreneur unintentionally makes economic society progress. Entrepreneurship is not only relative with entrepreneur's personal interest, but also economic society of the entire human.
\end{abstract}

\section{Keywords}

Austrian School, Market Process, Entrepreneurship

\section{Introduction}

In Austrian economic theory, entrepreneurship has always been a key factor. The attention to entrepreneurship is a tradition of the Austrian school, which can be traced back to the analysis of entrepreneurship by the founder of the Austrian school Carl Menger [1]. With the Austrian school's view of the market process, the entrepreneurship can get more realistic economic analysis in the background of the market process. But in the static equilibrium framework of mainstream economics, entrepreneurship doesn't even exist. It is difficult to harmonize entrepreneurship and static equilibrium, and it is difficult to analyze entrepreneurship in the framework of equilibrium. Entrepreneurs are themselves a driving force for change and response to market changes, constantly driving market processes. Entrepreneurship and market processes are two inseparable concepts. In the process of constantly changing market variables, profit-driven entrepreneurs bear uncertainty and compete for profits. In fact, prod- 
uct research and development, technological innovation and so on are the means for entrepreneurs to pursue profits. Product competition and technological competition are derived from entrepreneurs' competition for profits. In the market process, profit-seeking entrepreneurs constantly promote the evolution of economic structure, making the emerging economic structure better than the original economic structure, and thus promoting the human needs to be better met. It is clear that entrepreneurship represents a force for progress, and as the Austrian economist Ludwig von mises has argued, it is also a promoter.

This article is organized as follow: the relationship between market process and entrepreneurship, entrepreneurs who assume uncertainty, entrepreneurs create capital structure, and conclusion. All of them will disclose the importance of entrepreneurship which is ignored in mainstream economics.

\section{The Relationship between Market Process and Entrepreneurship}

According to the Austrian school, the concept of equilibrium is merely a thinking tool for studying market phenomena, rather than the core of studying market processes. Real value of the equilibrium concept should not be underestimated, but it is just a tool to solve the problem [2]. In the real world, while the market's tendency towards equilibrium, but because of various conditions and factors, such as resources, technology, people's preference, etc., are changing, so before achieving equilibrium in the market, the equilibrium of trend will be intervened by a variety of changes. Accordingly, the market will move towards the newly created equilibrium. Therefore, in the changing real world, the market is a dynamic process towards equilibrium, rather than a static state and close to equilibrium [3]. The Austrian school insists on seeing the market as a dynamic process rather than a balanced view of the market: "the market is not a place, a thing or a collection. The market is a process, created by all kinds of people working together under the interactive act" [4]. When the market is regarded as a dynamic process, there is room for entrepreneurship in the analysis of economics. Only in the background of the market process can we discover and explore the entrepreneurship in line with the real world of human beings.

According to the Austrian theory, human behavior has a purpose. In the market process, it means that the plans of people and people will not be fully coordinated and corresponding, because people act according to their own purposes. It is natural that the purposes of different people will not be completely consistent, and the objective material world in which people live is constantly changing. Therefore, in the market process, people's behavior, resource allocation and production structure need to be coordinated constantly. However, the entrepreneur plays a coordinating role. Under the guidance of price signal, he recognizes the total cost of input factors and the benefits of output, and predicts the profit opportunities between the current factor supply and the future product demand. The emergence of profit opportunities means that there exists an 
opportunity to coordinate the behavior of different people, while entrepreneurs who pursue profits will coordinate the behavior of people in the market process and make people and various resources find their place in the division of labor and cooperation in the market. Therefore, entrepreneurship is also reflected in the coordination process triggered by entrepreneurs. As the Austrian school economist Kerzner put it, "entrepreneurs bring a mutual adjustment into the uncoordinated elements that originated from previous market ignorance" [5]. Of course, entrepreneurs may also fail in coordination and suffer losses. In a state of equilibrium, where profits have disappeared, there is no opportunity for entrepreneurs to coordinate their actions with each other, and there is no need for entrepreneurship.

In contrast, perfect competition model of new classical economics, including all kinds of variations, the monopoly competition model, for example, there is no uncertainty in these models, just under the complete information, the "rational man" with a given the means to achieve a given goal, it has default that actions are coordinated between person and person, without the entrepreneur's coordination, it explore the equilibrium conditions and status. In other words, in the perfect competition model, resource allocation, human behavior and so on have been hidden in the conditions of the model. The rest is only to solve the optimal problem, and everyone becomes a negative "robot". This is highly criticism put forward by the British economist Robbins "economic calculation", namely "depending on the market by a large number of economic calculation of the people, each of them according to a given series of ends and means make their own decisions" [5]. And Kerzner think that actor's goal and means is open, not closed and given. The model of perfect competition in neoclassical economics places too much emphasis on static equilibrium analysis, emphasizes the equilibrium state and its conditions, and ignores human action and the process of tending to equilibrium, thus obliterating the important function of smart and alert entrepreneurs in the real market. Entrepreneurship is not reflected in how an entrepreneur acts within a given framework of means and goals, but in how the entrepreneur responds to changes in means and goals.

In the real world, as Mises saw it, entrepreneurs are the agents that drive market processes. Markets are a process, not a static state. New market boundaries require entrepreneurs to exploit; The uncertainty that arises constantly needs entrepreneurs to take on; Unbalanced market conditions require entrepreneurs to resort to economic activities such as production and trading to eliminate them. The objective material factors of production will not be automatically combined to produce products. Therefore, the production process needs the participation of entrepreneurs who integrate resources. In the complete information world without uncertainty, entrepreneurship does not exist. It exists only in the market process full of uncertainty. Therefore, only in the dynamic market process, entrepreneurship can obtain economic analysis. With certainty of new classical economics, therefore, the mathematical model is hard to become a tool to explore the theory of entrepreneurship, because there is no 
uncertainty of mathematical model, and entrepreneurship means that the change of means, the change of the purpose and the market environment which is full of uncertainty. "math does not provide any information that we need to achieve the static equilibrium" [2]. Without change, entrepreneurs do not have to make new decisions, but repeat past actions.

The market process is a discovery process. In the case of incomplete information, as Hayek put it, "what is scarce, or what is commodity, or how scarce or valuable, is exactly what needs to be found in the market" [6]. All these are not given information, but the discovery of entrepreneurs who need to participate in the competition. The market process is also a competitive process driven by the entrepreneur, which includes the competitive spirit. Entrepreneurs from the same industry and from different industries are moving in the market to try to outpace their competitors and provide better products for those in need. The market process is also a selection process, "where markets make people rich or poor, decide who can run big factories, who can scrub floors for others, and how many people mine copper and how many people join symphonies. These decisions are not set in stone, but can change at any time" [4]. In this regard, the entrepreneur is also facing the choice of the market. He needs to adjust production and adapt to the market change. It can be seen that dynamic market process and static equilibrium are opposite concepts.

In short, according to the Austrian school, entrepreneurship only exists in the market process, and at the same time, it also drives the operation of the market process. Without market processes, there is no entrepreneurship. Without entrepreneurship, there is no market process. Market processes and entrepreneurship are inseparable.

\section{Entrepreneurs Who Assume Uncertainty}

One of the character of entrepreneurship, says Mises, is that entrepreneurs assume uncertainty about business. The "uncertainty" that Mises refers to is unquantifiable, that is, his unquantifiable Case Probability [4] (Case Probability), which is the same meaning as the uncertainty mentioned by Knight. Uncertainty is different from risk. The former is unique and involves heterogeneous events. The latter is quantifiable and involves the same kind of events. The probability of risk occurrence can be calculated by using prior probability or empirical event. But the real uncertainty is unquantifiable, and people can't get the probability distribution of uncertainty. The Knight-Mises entrepreneur bears this unquantifiable uncertainty. Because the production and transaction activities of entrepreneurs are not homogeneous events, but occur in their unique space and time environment, which indicates that heterogeneous entrepreneurial activities must contain heterogeneous uncertainties rather than homogeneous risks. Both the profits and losses of entrepreneurs come from the uncertainty they assume. Only the existence of uncertainty can lead to the existence of profits, and the profits linked to uncertainty will provide incentives for entrepreneurs, so entrepreneurs are willing to bear uncertainty to carry out production activities. 
The normal operation of market economy must require entrepreneurs to bear uncertainty. In the market process, market conditions are always changing, and continuous changes generate continuous information flow, while people cannot obtain complete information. Therefore, future results and trends are not a quantifiable probability event, but a pure uncertainty. While the future is uncertain, entrepreneurs can predict it subjectively. According to Hayek's theory of knowledge, each person only has scattered information in a unique space and time environment [7]. Entrepreneurs guide the allocation of resources based on the decentralized information they have, coupled with their subjective judgment, and bear the uncertainty of their results. In the process of market, the market (market data) changes continuously, and people's preferences, resources and technology are always changing, all of them are uncertainty, which requires entrepreneurs integrate personal judgment, the decentralized information and resources to constantly adjust production activities, coordinate action between person and person, in order to cope with the future market conditions. Entrepreneurs themselves also actively induce change, such as Schumpeter's "creative destruction", and the consequences of that change are uncertain. In both of these changes, entrepreneurs are driving the market process. In the market process, Because of incomplete information, the individual judgment of the entrepreneur is very important. It is the guide of his action to deal with the ubiquitous uncertainty.

In addition, the behavior of an entrepreneur is oriented towards the unknown future. The production decisions he made in the past and present are all to meet the demand of future products, and he is bound to encounter uncertainty. As emphasized by the Austrian school, time is an inevitable factor to be considered in the action of the actor. All actions take place in the passage of time [4]. The production activities of entrepreneurs are no exception. The entrepreneur stands at the present time point, he needs to estimate the cost of input factors, the demand and price of products and other factors, so as to discover the uncertain profit opportunities in the future time and space. The goods that demand people buy now depend on the production decisions that entrepreneurs have made in the past. Moreover, the future demand of people is uncertain, and it must be borne by the entrepreneurs who estimated the possible demand in the future. In this sense, if not entrepreneurs to accurately estimate the future of humanity needs, human production activities will lose the direction. Entrepreneurs who bear the uncertainty in the past and the present production activities play a crucial role in meeting human uncertainty demand.

In the market process, in addition to the uncertainty brought by them, entrepreneurs are also engaged in risk division. There is also a division of risk between the entrepreneur and the factor provider, and between the entrepreneur and the entrepreneur, each taking on different risks. Different businesses have different risks, and different entrepreneurs are good at taking different risks, because only certain entrepreneurs have the information, resources and personal judgment in their unique space and time environment. These unique informa- 
tion, resources and personal judgment are not possessed by others. Entrepreneurs reallocate risky resources to specific people taking specific risks. For example, vegetable farmers and entrepreneurs have a contract in which entrepreneurs buy farmers' produce as required by the contract. It is a risky asset in terms of uncertain fluctuations of produce prices and demand. After signing the contract, vegetable farmers are faced with the risk of entrepreneur's default, while entrepreneurs are faced with the demand risk and price risk of agricultural products. These two kinds of risks were originally faced by vegetable farmers, but now they are transferred to entrepreneurs. Therefore, the emergence of entrepreneurs has led to the reallocation of risky assets.

Entrepreneurs assume uncertainty in their business activities. What then determines whether they succeed in assuming uncertainty? Under the profit and loss mechanism of the market, the judgment criterion is whether the entrepreneur gains profits. "the reason why an entrepreneur gains profits is that he can predict the future market conditions more accurately than other entrepreneurs" ([4], p. 319), which is also an afterthought criterion. No one can know for sure whether an entrepreneur can make a profit until he or she carries out production activities and obtains results, due to its unquantifiable uncertainty. In the process of market competition, to obtain profits, entrepreneurs are required not only to estimate uncertainty accurately, but also to take practical actions according to the estimation and adjust the combination of production means to adapt to the future situation. Under the profit and loss mechanism of the market, entrepreneurs without accurate estimation uncertainty will be gradually eliminated.

Entrepreneurs who successfully predict and assume uncertainty can continue to hold capital and factors of production, while those who fail gradually run out of money, or even go bankrupt, and give up on factors of production. Therefore, although the outcome of the entrepreneur's production activities is uncertain, it does not mean that the entrepreneur's production activities will fall into a blind and chaotic predicament. Because the market process is also a selection process, it will select entrepreneurs who are good at predicting the uncertain future of market conditions and maintain their production activities. Therefore, in the market process, the profit and loss mechanism effectively ensure that entrepreneurs who are more capable of forecasting and bearing uncertainty can gradually occupy the market, which is an elimination mechanism. After obtaining uncertain results, the profit and loss mechanism effectively prevents entrepreneurs from continuing to invest production factors in the wrong production direction.

Finally, to assume the uncertainty of productive activity, the entrepreneur must own the means of production. This is contrary to what Kerzner claims. He believes that entrepreneurship does not require entrepreneurs to have ownership of the means of production, and proposes the concept of "pure entrepreneur" who is responsible for finding profit opportunities without the means of production. Instead, another Austrian economist Henry Hazlitt argues that without the ownership of the means of production, cannot explain why entrepreneurs losses, 
and the term "entrepreneurial alertness" just makes him to find opportunities to uncertain profits, while profit opportunities [1] requires the use of production means. Therefore, if the entrepreneur is to bear the uncertainty of production activities, he must have the ownership of the means of production, without which he cannot take action to realize the possible profit opportunities.

\section{Entrepreneurs Create Capital Structure}

According to the Austrian school, capital is not homogeneous but heterogeneous, and heterogeneous capital cannot be viewed from an accounting perspective. What capital presents in society is the structural characteristics, namely capital structure. Accounting standards can be used to estimate the monetary value of capital goods, but it doesn't know that the capital structure behind the capital value, as the Austrian economist Rahman's point of view, "the change of the total value is the standard of our success, but it does not tell us what happened and why will happen, just as a thermometer does not tell us whether patients suffering from malaria or flu" [8]. Machines, factories and other capital goods are not spontaneously combined, but entrepreneur according to his purpose and plan, makes capital structure produce products that satisfy people's desire, so the capital structure reflects the purpose and plan of entrepreneur. Entrepreneurship is reflected in the heterogeneity of the capital structure, which makes it possible to have capital structure that has higher value.

In the Austrian theory of capital, capital has always been heterogeneous. Karl . Menger, the founder of the Austrian school, used the stage of production to rank economic goods. The consumer goods are the first order goods, and the production that are made up of the consumer goods are the second order goods, and the production that are made up of the second order goods are divided into the third order, and so on, the further away from the consumer goods, the capital goods are the higher order goods. Capital goods in different orders are naturally heterogeneous and play different service flows in different stages. Later, BhmBawerk argument that capital goods made possible more circuitous production phases, which led to higher output, or to products that could not be produced in the original production. In the further development of the capital theory by the economists of the Austrian school, capital is considered to contain the structure of entrepreneur's subjective plan, and has such heterogeneity characteristics as durability, complementarity and multiple specificity [8]. Since capital is heterogeneous and cannot be combined by itself, it provides entrepreneurs with space for portfolio capital. Only people's purposeful efforts and the pursuit of improving the production situation can combine them into the production process [4]. However, compared with the capital theory of mainstream economics, capital is generally regarded as homogeneous. In Clark's capital theory, it is a homogenous fund that can appreciate by itself [9], while in the Solow economic growth model of neoclassical economics, the capital structure completely disappears in the macro view, leaving only the homogeneous capital $\mathrm{K}$ in the equation. In the homogeneous capital view, there is no effect of human 
action on accumulation capital and portfolio capital, and "as long as we do not consider the heterogeneity of capital, the real function of entrepreneurs will be hidden" [8].

In the market process, since all information is not given and the evolution path of things is unknown, it provides space for entrepreneurs' creativity. Heterogeneous capital goods need to be put together by entrepreneurs to form a productive capital structure and align it with the needs of people. Because capital goods have complementarity and multiple specificity, under the uncertain changes in the market process, profit-seeking entrepreneurs will constantly adjust capital structure, or adopt complementary capital goods to expand capital structure, or use capital goods with multiple specificity for other production processes. In the above two structural changes, the change of the market environment itself will not drive the change of the capital structure, the real driver is the entrepreneur who perceives the change and profit opportunity, and how much value the capital structure that will generate depends on the actions of the entrepreneur, not the capital structure itself. In addition, entrepreneurs are trying to proactively change the capital structure to make it more profitable. Therefore, entrepreneurs can be the designers and architects of capital structure. Oriented by market demand and profit, they input the factors of production with lower total value to obtain the output with higher total value. But, because of the uncertainty, profit-seeking entrepreneurs may suffer from losses.

In the same production process, when the amount of capital exceeds a certain limit, the amount of new capital increases, then the marginal value generated by the combination of new capital goods and labor force decreases. The conventional wisdom is that new technologies can be used to improve productivity, thereby delaying the arrival of a period of diminishing marginal value, which is similarly skewed towards the homogeneity of capital. In the market process, another important role of the entrepreneur is to transfer the capital goods with multiple specificity to the new production process, rather than the existing production process. The combination of new capital structure also delays the arrival of the stage of diminishing marginal value. Entrepreneurs explore new market boundaries, explore new market demands, discover new profit opportunities, and then construct new capital structure. In the new capital structure, new capital goods that meet new demands will bring greater value. New capital structures, and new market boundaries, cannot be created on their own and can only be discovered and created by entrepreneurs. Therefore, this non-technical method is discovered and adopted by entrepreneurs rather than the credit of technical personnel. Without changing the technical efficiency of capital, entrepreneurs change the combination of multiple capital and explores the new market.

Furthermore, in Mises's view, an entrepreneur's capital can also be altruistic, creating a capital structure that actually serves others, not himself. In Adam Smith's theory of self-interest, the self-interested action of man can produce an altruistic effect. Smith famously wrote, "the food and drink we need every day is not the favor of the butcher, the winemaker, and the baker; it is out of their own 
self-interest. We speak not arouse their altruistic heart, while said to raise their self-interest" [10] Smith considering the effect of the self-interested actions of altruism, whereas Mises insight into entrepreneur's private capital can also be altruistic effects, they are in the service of others, Mises wrote: "like to drink coffee, I don't have to have Brazil's small factory, ocean-going freighter and coffee, even though the means of production are needed for this coffee in front of me, someone else has these means but to me and use them, it's enough... All the means of production serve everyone who buys and sells in the market." [11] therefore, in Mises's point of view, although the ownership of the capital structure belongs to capitalists and entrepreneurs, the capital structure itself cannot directly satisfy the owner's desire, and capital structure provides services to those who need the output. Entrepreneurs invest in capital goods such as plants, machinery and equipment to build capital structures with production functions, but no matter how great their value, they are ultimately the ones that serve the demand for others, not the entrepreneurs themselves. In addition, their value is closely related to whether they can meet the demand of demanders. Only by better meeting the demanders can the market value of the entire capital structure be improved. In the securities market, this can be reflected in the increase of the market value of listed companies.

Therefore, the capital structure of entrepreneurs and self-interested entrepreneurs are ultimately to provide services for others and meet the needs of others. "In a market society, all economic affairs are directed by entrepreneurs," Mises writes in his book Human Act. "They control production. They are the coxswain and driver of the big ship. Shallow observers may think they are on top. But that's not the case. They must obey the captain's orders without question. And the captain is the consumer... If a businessman does not strictly obey the instructions that the mass consumer conveys to him with the help of market price structure, he will suffer losses, go bankrupt and thus retire from the position of eminent helmsman." [4]. This is what Mises calls Consumer Sovereignty. Regardless of the production stage and capital structure, they are to produce the final consumer goods. Therefore, the capital structure can be maintained if consumers are better satisfied. The role of entrepreneurs is to realize the better capital structure and make it available to the demanders.

In fact, it is not only the enterprises and factories of entrepreneurs that have a capital structure within them. In the whole economic society, the capital structure exists between enterprises and enterprises. Behind the product transaction between different enterprises, the essence is the matching of capital structure between different enterprises. In the market process, there is no one to command the productive activities of all entrepreneurs or to arrange the structure of the whole social capital structure, which is changing from moment to moment. The capital structure of entrepreneurs forms a huge network of social capital structure, but the highly complex network of capital structure does not fall into the chaos of production, because entrepreneurs are responsible for coordinating functions and the existence of market profit and loss mechanism. 
Under the price signal, the entrepreneur perceives the arbitrage opportunity between the total value of factors and the total value of output. The existence of arbitrage opportunity indicates that the entrepreneur can coordinate the supply side of factors and the demand side of output as well as the different capital structure. The profit and loss mechanism of the market can gradually disintegrate the wrong capital structure or change its use, while the right capital structure can gradually expand or be maintained. So, in the process of market, the profit and loss is also a clear mechanism, it gradually clean up the capital structure of society as a whole network. Price, profit and loss mechanism contains signal precisely, reflecting the people's needs and desires, this makes the capital structure is subject to the needs and desires of the people as much as possible. The change of capital structure should be tested by the profit and loss mechanism, so that the profitable capital structure can be integrated into the capital structure of the whole society, while the loss-making capital structure will gradually disintegrate or change its use, which means that it cannot produce favorable coordination with other capital structures. In the market process, due to the uncertainty and incomplete information, it is only possible to find the capital structure that meets people's needs and desires with the help of the entrepreneur's business risk activities, and judge whether the entrepreneur's business risk activities are successful through the profit and loss mechanism.

Therefore, entrepreneurs are responsible for combining capital, building capital structure, and coordinating the whole network of social capital structure, which belongs to capitalists and entrepreneurs but serves others. The capital structure contains the plan of entrepreneurs, and entrepreneurs externalizes the inner plan into the real capital structure by means of action and resources. The coordinated capital structure means the plan among entrepreneurs. Capital structures are not automatically created and need to be combined by profit-seeking entrepreneurs. In the market process, the capital structure of the society is undergoing dynamic evolution under the leadership of entrepreneurs to adapt to the uncertain changes of the market, and the entrepreneurs can obtain possible profits themselves. Meanwhile, human needs will be better satisfied accordingly. In this sense, entrepreneurs are the promoters of economic progress. "their goal is profit, and their means are to adjust their operations to the fullest extent to meet the needs of their consumers. In advancing their plans to achieve this progress, they must share the benefits of economic progress with the workers, as well as with some capitalists and landowners." [4].

\section{Conclusions}

From the theoretical perspective of the Austrian school, entrepreneurship plays a very important role in the market process, which is not only related to whether the entrepreneur can realize profits, but also related to the entire human economic society. In the economic society, production activities and arbitrage activities are intertemporal, and they are bound to encounter uncertainty in the future, which requires entrepreneurs to take the initiative to assume uncertainty, 
predict the future by personal judgment, input resources and adjust production to cope with the future. Moreover, since factors of production do not have free will and have to be combined by human beings, and entrepreneurs are responsible for this important function. They save consumption and accumulate savings, thus combining heterogeneous capital goods to create capital structure with production function.

In the market process, people's means and goals are open, which is not a given means and goals under the balanced framework, and the evolution process of economic things is not established and known, which provides space for entrepreneurs to creatively explore new boundaries of the market, produce new products, and discover new business opportunities. Entrepreneurs' quest for profits has unintentionally created a complex economic structure that allows consumers to be better satisfied. In the evolution of economic society, entrepreneurs play a crucial role as promoters. Under the constraint of resource scarcity, entrepreneurship is an indispensable and important quality for human wealth creation, which makes scarce resources better meet human needs. The more entrepreneurial the society, the more developed and prosperous the economy will be. Entrepreneurship is not in the fictitious equilibrium world, but in the real dynamic market process. It is a spiritual force that promotes economic evolution.

\section{Conflicts of Interest}

The author declares no conflicts of interest regarding the publication of this paper.

\section{References}

[1] Joseph, T. (2008) The Entrepreneur: Real and Imagined. Quarterly Journal of Austrian Economics, 188-207.

[2] Ludwig, V.M. (2007) Money, Method and the Market Process. New Star Press, Beijing.

[3] Israel, M.K. (2012) The Meaning of Market Process. China Social Sciences Publishing House, Beijing.

[4] Ludwig, V.M. (2013) Human Action. Shanghai Century Publishing Co. Ltd., Shanghai.

[5] Israel, M.K. (2003) Competition and Entrepreneurship. Zhejiang University Press, Hangzhou.

[6] Friedrich, A.H. (2009) Hayek Selections. Jiangsu People’s Publishing House, Nanjing.

[7] Friedrich, A.H. (2003) Individualism and Economic Order. Joint Publishing, Beijing.

[8] Ludwig, L. (2015) Capital and Its Structure. Shanghai University of Finance and Economics Press, Shanghai.

[9] Jesus, H.S. (2010) The Austrian School: Market Order and Entrepreneurial Creativity. Zhejiang University Press, Hangzhou.

[10] Adam, S. (2014) The Wealth of the Nations. The Commercial Press, Beijing.

[11] Ludwig, V.M. (2008) Socialism. China Social Sciences Publishing House, Beijing. 